To the Editors:

\title{
Screening for gestational diabetes mellitus in Anuradhapura district
}

Ceylon Medical Journal 2011; 56: 128-129

Gestational diabetes mellitus (GDM) is defined as any degree of glucose intolerance with first recognition or onset during pregnancy regardless of whether diet modification or insulin used for treatment or if condition persists following pregnancy [1]. Even though national estimates on GDM prevalence are lacking in Sri Lanka, a study conducted in Homagama reported a community prevalence of $10.3 \%$ [2]. Ministry of Health and Nutrition of Sri Lanka practice guidelines recommend two hour postprandial blood sugar (2hPPBS) after standard meal at booking visits for those with risk factors for GDM as the screening test. It further states that if $2 \mathrm{hPPBS}$ is $>7.22$ $\mathrm{mmol} / \mathrm{L}$ proceed once to $75 \mathrm{~g}$ oral glucose tolerance test (OGTT), and if $<7.22 \mathrm{mmol} / \mathrm{L}$ with at least one risk factor to proceed to $75 \mathrm{~g}$ OGTT at 24-28 weeks [3].

We carried out a descriptive cross sectional study to explore GDM screening methods currently practiced in Anuradhapura district from February to May 2010. The study population included pregnant mothers with a period of amenorrhoea 24 weeks or more and residing in Anuradhapura district. Participants were selected from field antenatal clinics using a two stage cluster sampling procedure. Twenty Public Health Midwife areas were selected from three Medical Officer of Health $(\mathrm{MOH})$ areas in Anuradhapura district. Sample size was calculated to detect $10 \%$ prevalence of GDM with $5 \%$ precision and
95\% confidence interval. Data were collected using an interviewer administered, structured questionnaire and perusing ante-natal records after obtaining verbal consent. Approval for the study was obtained from the Ethical Review Committee, Faculty of Medicine and Allied Sciences, Rajarata University of Sri Lanka.

A total of 223 pregnant mothers were studied. There were 96 mothers with at least a single risk factor for GDM. These included current pregnancy indications in 81 (36.3\%), previous pregnancy indications in $23(8.1 \%)$ and mothers with first degree relatives with type 2 diabetes mellitus, 25 (11.2\%). Only 29 (30.2\%) mothers with risk factors had any type of standard screening test (Table 1). This included PPBS $26(27.1 \%)$ and OGTT $3(3.1 \%)$. However, only 6 mothers had PPBS during the first trimester. In the present sample, there were no mothers with GDM.

The guidelines issued from the Ministry of Health have not been followed in GDM screening in Anuradhapura district and risk assessments were limited to documentation without further actions. Thus GDM was grossly under-diagnosed. Educating the health care professionals on GDM screening and proper follow-up is recommended as an urgent measure to improve maternal and child health services in Anuradhapura.

Table 1. Distribution of risk factors for GDM in the study sample

\begin{tabular}{lccc}
\hline Screening test & $\begin{array}{c}\text { With riskfactors } \\
(n=96)\end{array}$ & $\begin{array}{c}\text { Without risk factors } \\
(n=127)\end{array}$ & $\begin{array}{c}\text { Total } \\
(n=223)\end{array}$ \\
\hline Urine Dipstick & $94(97.9 \%)$ & $125(98.4 \%)$ & $219(98.2 \%)$ \\
FBS & $7(07.3 \%)$ & $4(03.1 \%)$ & $11(4.9 \%)$ \\
RBS & $4(04.2 \%)$ & $2(01.6 \%)$ & $6(2.7 \%)$ \\
PPBS & $26(27.1 \%)$ & $17(13.4 \%)$ & $43(19.3 \%)$ \\
GCT & 0 & $1(0.8 \%)$ & $4(1.4 \%)$ \\
$75 g$ OGTT & $3(03.1 \%)$ & $1(0.8 \%)$ & $61(27.4 \%)$ \\
Any Blood Sugar & $37(38.5 \%)$ & $24(18.9 \%)$ & $4 \%)$ \\
\hline
\end{tabular}

FBS $=$ Fasting blood sugar, RBS $=$ Random blood sugar, PPBS = Postprandial blood sugar, GCT = Glucose challenge test, OGTT $=$ Oral glucose tolerance test. 


\section{References}

1. American Diabetes Association. Diagnosis and classification of diabetes mellitus (Positional Statement). Diabetes Care 2009; 32(Sup 1): 62-7.

2. Ginige S, Wijewardena K, Wijerathna CN. Prevalence of Gestational Diabetes Mellitus in Homagama Divisional
Director of Health Services area. Journal of the College of Community Physicians of Sri Lanka 2004; 9: 40-2.

3. Ministry of Healthcare and Nutrition: Diabetes complicating pregnancy. In: Management of Diabetes Mellitus National Guidelines. Colombo: Ministry of Healthcare and Nutrition Sri Lanka, 2007: 39-41.

\section{N J Dahanayaka', S B Agampodi², O R J C Ranasinghe'1, P M E D Jayaweera', S Fernando²}

${ }^{1}$ Department of Medicine, Faculty of Medicine and Allied Sciences, Saliyapura, ${ }^{2}$ Department of Community Medicine, Faculty of Medicine and Allied Sciences, Saliyapura, Sri Lanka.

Correspondence: NJD, e-mail: <niroshanajd@yahoo.com>. Received 15 November 2010 and revised version accepted 15 March 2011. Competing interests: none declared. 